\title{
Desempenho na barra de tração de um trator agrícola de pneus, alimentado com misturas de óleo diesel e óleo de soja reutilizado
}

\author{
Wagner da Cunha Siqueiral, Haroldo Carlos Fernandes², Mauri Martins Teixeira ${ }^{3}$, \\ Nerilson Terra Santos ${ }^{4}$, Selma Alves Abrahão ${ }^{5}$
}

\section{RESUMO}

O petróleo é a principal fonte de energia para motores de combustão interna, possibilitando sua transformação em energia mecânica. A dependência do petróleo conduz à necessidade de alternativas, mediante o cultivo de matériasprimas renováveis. Os problemas atuais são os custos dos biocombustíveis, que são maiores que dos derivados do petróleo, e o fato de que não existem muitos motores de combustão adequados ao uso de óleos vegetais. Em vista disso, são necessárias mais investigações quanto às técnicas de produção e de refino dos biocombustíveis e, ainda, à adequação de motores ao uso de óleos vegetais, para que estes possam ser uma alternativa viável. O objetivo deste trabalho foi caracterizar as diferentes misturas e avaliar o desempenho de um trator agrícola de pneus, utilizando misturas de óleo Diesel (OD) com óleo de soja reutilizável (OSR). Primeiramente, foi realizado um estudo de densidade, viscosidade das misturas e comportamento da temperatura do OD no sistema de alimentação de combustível no motor. Após as análises, verificou-se, por meio de ensaios na barra de tração, o desempenho das misturas de OD e OSR. As principais conclusões deste trabalho foram: a densidade e viscosidade das misturas sofrem variações com o aumento da quantidade de OSR e com a variação da temperatura. Para as avaliações na barra de tração, os melhores resultados observados no rendimento do trator foram verificados com o aumento das percentagens de mistura (25\% OSR, para carga N, 25, 75 e 100\% OSR, para a quarta marcha, como carga, e 75 e 100\% OSR, para a terceira, segunda e primeira marcha, como carga).

Palavras-chave: biocombustíveis, potência, consumo.

\section{ABSTRACT \\ Performance on the traction of an agricultural tractor drive tires fed with mixtures of petroleum diesel and reused soybean oil}

Petroleum is the main source of energy for internal-combustion engines, enabling its transformation into mechanical energy. Oil dependence leads to the needs of alternatives, through the cultivation of renewable raw materials. The current problems are the costs of biofuels, which are higher than those derived from petroleum, and the fact that there are few combustion engines suitable for vegetable oils. Thus, further research on the techniques of production and refining of biofuels, and the suitability of engines using vegetable oils are necessary, so that they can be a viable alternative. Therefore, the objective of this study was to characterize different mixtures and to evaluate the performance

Recebido para publicação em 28/04/2011 e aprovado em 01/08/2013.

1 Engenheiro Agrícola, Mestre. Departamento de Engenharia Agrícola, Universidade Federal de Viçosa, Campus Viçosa, Avenida Peter Henry Rolfs, s/n, 36570-000, Viçosa, Minas Gerais, Brasil. wagnercsiqueira@yahoo.com.br (autor para correspondência).

2 Engenheiro Agrícola, Doutor. Departamento de Engenharia Agrícola, Universidade Federal de Viçosa, Campus Viçosa, Avenida Peter Henry Rolfs, s/n, 36570-000, Viçosa, Minas Gerais, Brasil. haroldo@ufv.br

3 Engenheiro-Agrônomo, Doutor. Departamento de Engenharia Agrícola, Universidade Federal de Viçosa, Campus Viçosa, Avenida Peter Henry Rolfs, s/n, 36570-000, Viçosa, Minas Gerais, Brasil. mauri@ufv.br

4 Engenheiro-Agrônomo, Doutor. Departamento de Informática, Universidade Federal de Viçosa, Campus Viçosa, Avenida Peter Henry Rolfs, s/n, 36570-000, Viçosa, Minas Gerais, Brasil.nsantos@ufv.br

5 Engenheira Agrimensora, Mestre. Departamento de Engenharia Agrícola, Universidade Federal de Viçosa, Campus Viçosa, Avenida Peter Henry Rolfs, s/n, 36570-000, Viçosa, Minas Gerais, Brasil. easelma@yahoo.com.br 
of an agricultural tractor drive tires, using mixtures of petroleum diesel (OD) with reused soybean oil (OSR). At first, we conducted a study of density, viscosity of the mixtures and behavior of the temperature of the OD in the system of fuel supply of the engine. After analyses, the performance of the mixtures of OD and OSR was verified by assays in the traction bar. The main conclusions of this study were: the density and viscosity of the mixtures undergo variations with increasing amount of OSR and temperature variation. Regarding the evaluations in the traction bar, the best results were observed for the yield of the tractor were verified with the increase of the mixture percentages (25\% OSR to load N, 25\%, 75\% and 100\% OSR for the fourth gear, as load and 75\% and 100\% OSR for third, second and first gear as load).

Key words: biofuel, power, consumption.

\section{INTRODUÇÃO}

Uma das tarefas atuais dos pesquisadores é a busca por novas fontes energéticas, para atender ao período de transição do petróleo para combustíveis não fósseis. Esse fato depende de cada país, de cada região mundial e de cada condição climática. Para mudança da política energética, são necessários não só grandes investimentos, como longos prazos de maturação e de pesquisas para produção dos novos combustíveis, em uma escala suficientemente capaz de atender à demanda prevista para os próximos anos (Lima \& Marcondes, 2002).

Vidal (2009) prevê que os óleos vegetais irão substituir o petróleo. De acordo com o mesmo autor, isso resultaria em maior autonomia do pequeno produtor rural, uma vez que ele promove o desenvolvimento econômico e social regional, reduz as emissões de poluentes, o que, para a atividade agrícola, significa serem utilizados menos derivados de petróleo, e a montagem de uma rede descentralizada de produção de energia, gerando milhões de empregos.

A produção de óleos vegetais é de fácil tecnologia e de amplo conhecimento, podendo ser oriunda de uma prensagem mecânica, seguida de filtração para retirada de resíduos e impurezas. Os óleos são extraídos de diferentes tipos de sementes e são utilizados como alimentos; são produtos de grande interesse econômico e objeto de intensa atividade comercial. São misturas de substâncias gordurosas (ácidos graxos), de origem vegetal ou animal, e têm aplicações restritas (animal) e amplas (vegetal) na alimentação humana (Wust, 2004).

Para Fender (2009), a utilização do óleo vegetal in natura poderá apresentar vantagens em relação à do biodiesel, com possibilidade de total independência dos derivados de petróleo; não requer investimentos de longo prazo, em especial, com equipamentos, e apresenta imediato retorno do capital empregado e incentivo à produção de sementes oleaginosas.
Segundo Inoue (2008), a produção do combustível de origem vegetal apresenta vantagens de não necessitar de reagentes, permitir o aproveitamento das espécies oleaginosas encontradas na propriedade, além de aproveitar os resíduos para a alimentação de animais ou na forma de adubo orgânico.

O uso de óleos vegetais em motores de combustão interna, automotivos e estacionários, como alternativa ao óleo diesel, implica significativos ganhos sócioambientais, pois, trata-se de um recurso renovável de origem agrícola (Faria, 2010).

Objetivou-se, com este trabalho, caracterizar as diferentes misturas de óleo Diesel (OD) e óleo de soja reutilizado (OSR) e avaliar o desempenho, na barra de tração, de um trator agrícola de pneus.

\section{MATERIAL E MÉTODOS}

Este trabalho foi realizado no Laboratório de Mecanização Agrícola (LMA) do Departamento de Engenharia Agrícola (DEA), da Universidade Federal de Viçosa (UFV), no período de janeiro a fevereiro de 2010. Foi avaliado o desempenho, na barra de tração, de um trator agrícola de pneus, marca Valmet, modelo 65ID, Motor MWM, modelo D225-3TV, 4 tempos, injeção direta, refrigerado a água, camisas úmidas removíveis, com 3 cilindros verticais em linha, cilindrada total de 2.829 $\mathrm{cm}^{3}$, relação de compressão $18: 1$, ordem de ignição 1-32 , rotação máxima de 2.300 RPM e potência nominal igual a $42,65 \mathrm{~kW}$, com 8.358 horas trabalhadas, tendo, como principais dimensões, rodagem traseira de 14,9/ 13-28", 6 lonas, rodagem dianteira de 7,5-16", 6 lonas, comprimento do trator de $3,02 \mathrm{~m}$, distância entre eixos de $1,94 \mathrm{~m}$, altura da barra de tração de $0,4 \mathrm{~m}$, peso traseiro estático de $166,3 \mathrm{~N}$, peso dianteiro estático de $87,7 \mathrm{~N}$, sendo alimentado por diferentes teores de misturas de OD e ORS provenientes do restaurante universitário da UFV. 


\section{Combustíveis utilizados}

Para que o OSR pudesse ser utilizado nas misturas com o OD, ele passou por diversos processos, como decantação, filtragem, lavagem e fervura, com a função de retirar impurezas e partículas indesejáveis, como sal, açúcar, água e gordura animal.

Para a realização das avaliações, foram usadas misturas de OD com OSR nas proporções de 0\% OD e 100\% OSR; $25 \%$ OD e $75 \%$ OSR; $50 \%$ OD e $50 \%$ OSR; $75 \%$ OD e 25\% OSR; $100 \%$ OD e 0\% OSR. As misturas foram separadas com base em peso e não em volume, de acordo com as densidades diferentes do OD e do OSR. Após pesadas, as misturas foram armazenadas em recipientes de cinco litros cada, devidamente identificados.

\section{Determinação da massa específica do combustivel}

Para a determinação do consumo específico de combustível, foi necessário o conhecimento da massa específica das diferentes misturas utilizadas.

Foi utilizada uma proveta com capacidade de 100 $\mathrm{mL}$ e precisão de $1,0 \mathrm{~mL}$, um termômetro com variação de 0 a $210^{\circ} \mathrm{C}$ e uma balança com capacidade para $300 \mathrm{~g}$ e precisão de $0,001 \mathrm{~g}$. A determinação iniciou-se com a pesagem do óleo e medição da temperatura da amostra (55 $\mathrm{mL}$ de volume, em temperatura ambiente). Essa amostra foi aquecida posteriormente até $120^{\circ} \mathrm{C}$ e o início do registro das leituras ocorreu quando a temperatura da mistura atingiu $90^{\circ} \mathrm{C}$. A cada $5{ }^{\circ} \mathrm{C}$ de decréscimo na temperatura, foi coletado o valor de sua massa e volume, até que a mistura retornasse à temperatura ambiente. Repetiu-se esse procedimento para todas as amostras.

\section{Índice de viscosidade do combustível}

Analisou-se o comportamento da viscosidade de diferentes misturas de OD e OSR, utilizando-se um viscosímetro de orifício do tipo Saybolt.

Para a determinação da viscosidade, foram utilizadas amostras, nas proporções descritas anteriormente. A conversão da unidade da viscosidade de Segundos Universais Saybolt (SUS), para a Viscosidade Cinemática (Centistokes) foi realizada por meio do Nomograma (Barguer et al., 1966); posteriormente, as viscosidades foram confrontadas com a Portaria ANP 310 (2001). As temperaturas utilizadas para se avaliar a viscosidade das misturas foram de 30,60 e $90^{\circ} \mathrm{C}$, de acordo com a variação da temperatura encontrada no sistema de alimentação, em avaliações anteriores.

\section{Poder calorífico do combustível}

Os testes de calorimetria foram realizados, utilizandose uma bomba calorimétrica marca The Parr Automatic
Adiabatic Calorimeter, pertencente ao Departamento de Engenharia Florestal da UFV.

Para a determinação do poder calorífico superior (PCS), os testes seguiram a norma ANSI/ASTM D 240 - 76.

\section{Ensaio na barra de tração (BT)}

A avaliação do desempenho do trator foi efetuada em uma pista de blocos de concreto, utilizando-se um comboio formado por dois tratores. $\mathrm{O}$ trator submetido ao ensaio foi dotado de um fluxômetro de combustível, com capacidade para $1.000 \mathrm{~mL}$ e célula de carga de capacidade máxima de $50 \mathrm{kN}$. As cargas aplicadas pelo segundo trator (trator lastro) foram visualizadas em um visor da marca Kratos.

A coleta dos dados, para a determinação das curvas de potência, velocidade, patinagem e consumo de combustível em função da força de tração, foi realizada variando as marchas no trator utilizado como lastro.

$\mathrm{O}$ ensaio foi realizado com o trator utilizando a $3^{\mathrm{a}}$ marcha reduzida e as cargas aplicadas pelo trator lastro foram: $\mathrm{N}$ (Neutro), $4^{\mathrm{a}}, 3^{\mathrm{a}}, 2^{\mathrm{a}}$ e $1^{\mathrm{a}}$ marcha simples. Para cada marcha do trator avaliado, foram utilizadas três repetições para cada carga empregada pelo trator lastro. A coleta de dados foi efetuada em uma pista de concreto de 30 metros de comprimento, sendo utilizados, antes do início da pista, cinco metros para estabilização do trator.

A coleta teve início no momento em que a roda motriz do trator passou pelo início da pista, começando-se, então, a contagem do número de voltas da roda motriz, tempo de percurso, consumo do combustível e leituras da célula de carga. A coleta encerrou-se com a passagem da roda motriz além da linha de 30 metros do percurso. Os dados foram tabulados com planilha eletrônica para ensaio na BT (Fernandes \& Santos, 2006), descrita na Figura 1.

Essa planilha considera a entrada de dados referentes às características do trator, bem como as informações obtidas durante o ensaio na barra de tração, como o tempo de duração do "tiro" (teste em determinada carga), consumo de combustível (mL), número de voltas da roda motriz e leitura da célula de carga. A partir desses dados, pode-se calcular a força de tração $(\mathrm{N})$, velocidade $\left(\mathrm{m} \mathrm{s}^{-1}\right)$, potência disponível na barra de tração $(\mathrm{kW})$, consumo horário $\left(\mathrm{L} \mathrm{h}^{-1}\right)$, consumo específico $\left(\mathrm{g} \mathrm{kW}^{-1} \mathrm{~h}^{-1}\right)$, patinagem (\%) e coeficiente de tração (\%), durante o ensaio de tração.

Para cada carga empregada no ensaio da barra de tração, automaticamente a planilha fornece as curvas de desempenho do trator, relacionando velocidade, potência, patinagem, consumo horário e consumo específico com a força na barra de tração do trator ensaiado, além do valor do coeficiente de tração desse mesmo trator. 


\section{Delineamento experimental}

Para o ensaio na BT, foi utilizado o delineamento inteiramente casualizado, a unidade experimental composta pelo intervalo de tempo gasto para o comboio percorrer um trajeto de 30 metros. Nesse intervalo, foram avaliados os valores das variáveis: força de tração, número de voltas do pneu, consumo horário de combustível e tempo de percurso.

Os resultados obtidos com a realização do experimento foram submetidos à análise de variância e à aplicação de teste de Tukey, para identificar a mistura que proporciona os melhores resultados nas variáveis de interesse. Foi adotada a significância de $5 \%$, com o programa computacional SAS versão 9.1.

\section{RESULTADOS E DISCUSSÃO}

\section{Massa específica do combustivel}

Por meio da análise de regressão, foram determinadas equações para se estimar a massa específica das misturas, nas diferentes temperaturas $\left(25\right.$ a $\left.90^{\circ} \mathrm{C}\right)$. Os modelos foram lineares e as estimativas das equações podem ser visualizadas na Tabela 1.

Os valores encontrados de massa específica das misturas ficaram na faixa de $0,811 \mathrm{a} 0,910 \mathrm{~g} \mathrm{~cm}^{-3}$, para temperaturas variando de 25 a $90{ }^{\circ} \mathrm{C}$. Verificou-se que a densidade diminuiu linearmente com o aumento da temperatura, com coeficiente de correlação superior a 97\%. O compor- tamento decrescente obtido com o aumento da temperatura é típico dos fluidos newtonianos. Comportamento semelhante também foi obtido por Castro (1999), quando estudou a densidade do azeite de babaçu.

Pode-se verificar, também, que a massa específica das misturas tendeu a ser maior quando ocorre o aumento da percentagem de OSR e diminuiu com o aumento da temperatura. A massa específica é a relação entre a massa e o volume de um corpo e, em geral, quando se aumenta a temperatura de um determinado fragmento de matéria, temse um aumento do volume fixo desta, pois haverá a dilatação ocasionada pela separação dos átomos e moléculas (Siqueira, 2010).

\section{Índice de viscosidade do combustivel}

Por meio da análise de regressão, foram determinadas equações para se estimarem as viscosidades das misturas, na faixa de temperatura de 30 a $90^{\circ} \mathrm{C}$ (Tabela 2), sendo que os modelos apresentaram-se lineares.

Os principais fatores que afetam a medida da viscosidade são: a natureza físico-química do líquido, a composição da mistura, a temperatura, a pressão, a taxa de cisalhamento, o tempo e o campo elétrico (Barnes et al., 1991).

Para comparação da viscosidade das misturas, utilizou-se, como referência, a Portaria ANP 310 (2001), referente à viscosidade do OD. A faixa de viscosidade recomendada pela ANP 310 fica entre 2,5 e $5,5 \mathrm{cSt}$, a $40^{\circ} \mathrm{C}$.

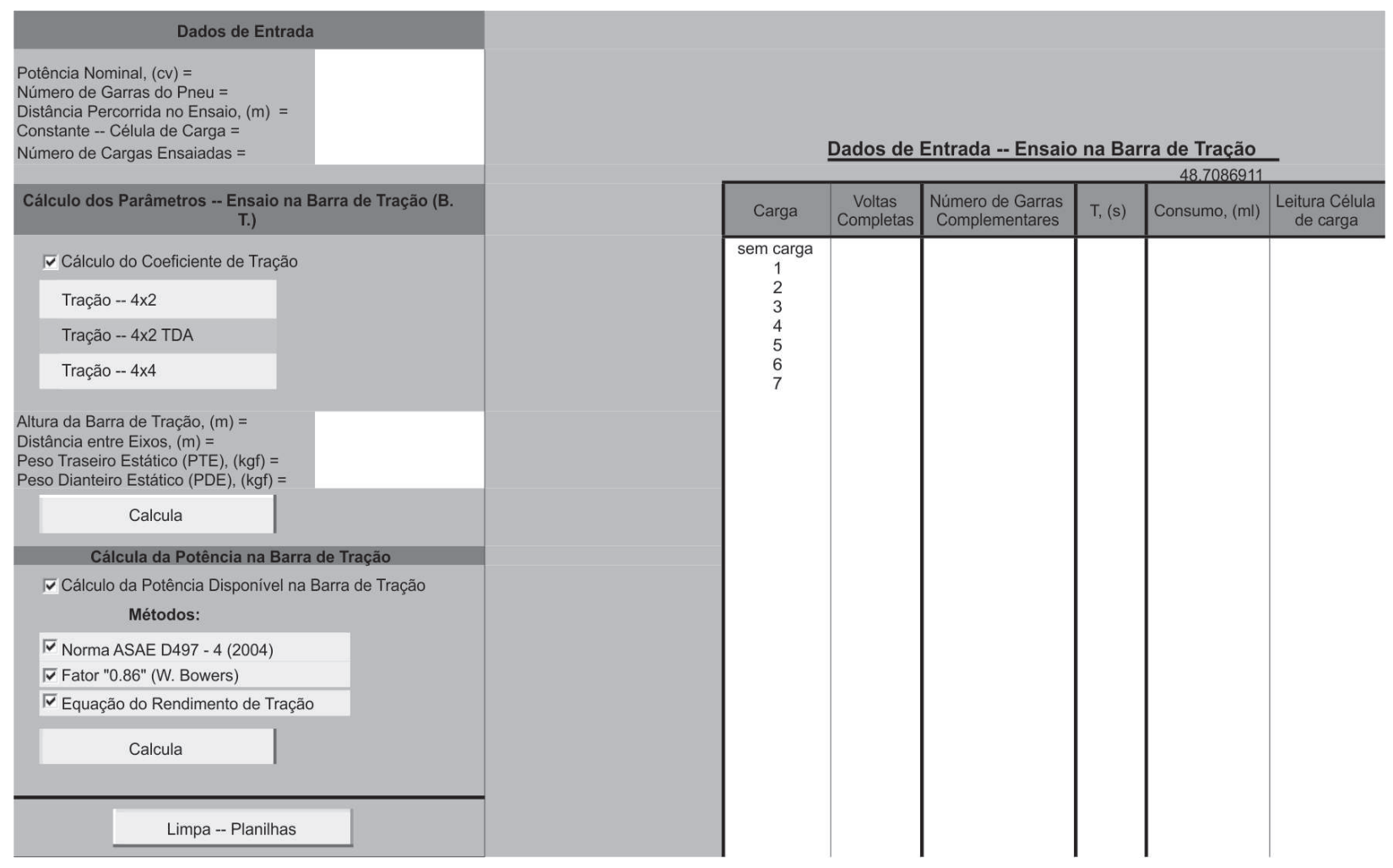

Figura 1. Tela de entrada de dados do ensaio na barra de tração.

Rev. Ceres, Viçosa, v. 60, n.6, p. 793-801, nov/dez, 2013 
Para uma condição de temperatura de $40{ }^{\circ} \mathrm{C}$, nenhuma das misturas utilizadas atendeu à Portaria ANP 310, o que pode ser explicado pelo fato de o OD ter a viscosidade cinemática perto do limite superior estabelecido pela Portaria. No caso das misturas aquecidas até $60^{\circ} \mathrm{C}$, a mistura de $25 \%$ OSR e $75 \%$ OD enquadrou-se na Portaria da ANP. Quando a temperatura foi elevada para $90{ }^{\circ} \mathrm{C}$, ocorreu redução na viscosidade de todas as misturas testadas, atendendo, assim, à faixa de viscosidade exigida pela ANP 310 .

O aquecimento do OSR, de 40 para $90^{\circ} \mathrm{C}$, reduziu em até $90,4 \%$ a sua viscosidade. Observou-se também que, quanto maior a proporção de OSR, maior a influência da temperatura na redução da viscosidade. Castro (1999), estudando a viscosidade do óleo de babaçu, verificou que a viscosidade decresceu consideravelmente em presença de altas temperaturas. Pramanik (2003) e Ribeiro et al. (2010) observaram comportamento similar para o óleo de pinhão-manso, no qual a viscosidade é reduzida com o aumento da temperatura.

\section{Poder calorífico do combustivel}

$\mathrm{Na}$ Tabela 3, estão apresentados os valores de poder calorífico superior (PCS) das cinco misturas testadas. Entre as amostras estudadas, a mistura que apresentou poder calorífico mais próximo ao do OD a de $25 \%$ OSR e $75 \%$ $\mathrm{OD}$, com variação de apenas $48 \mathrm{kcal}$. A variação do poder calorífico seguiu uma ordem decrescente, com relação ao OD, com o aumento do teor de OSR.

A mistura de $100 \%$ OSR apresentou o menor poder calorífico, correspondente a $83 \%$ do valor observado no OD, valor esse próximo ao encontrado por Knothe (2006). Para Knothe (2006), além do número de cetano, o calor de combustão é uma propriedade que demonstra a adequação dos vários tipos de compostos graxos para uso como combustível em motores Diesel. O calor de combustão dos óleos vegetais e de seus respectivos ésteres alquílicos corresponde a cerca de $90 \%$ do valor observado no OD derivado de petróleo.

\section{Avaliação na barra de tração (BT)}

Nas Tabelas de 4 a 9, estão apresentadas as médias obtidas para as variáveis força de tração $(\mathrm{N})$, velocidade $\left(\mathrm{m} \mathrm{s}^{-1}\right)$, potência $(\mathrm{kW})$, consumo horário $\left(\mathrm{L} \mathrm{h}^{-1}\right)$, consumo específico $\left(\mathrm{g} \mathrm{kW}^{-1} \mathrm{~h}^{-1}\right)$ e patinagem $(\%)$, em função das misturas $0,25,50,75$ e $100 \%$ OSR, quando o trator trabalhou submetido a seis diferentes cargas.

$\mathrm{Na}$ Tabela 4, estão apresentadas as médias obtidas para as variáveis, velocidade $\left(\mathrm{m} \mathrm{s}^{-1}\right)$, consumo horário ( $\mathrm{L}$ $\mathrm{h}^{-1}$ ) em função das misturas 0, 25, 50, 75 e 100\% OSR, quando o trator trabalhou sem carga. Verificou-se que, para todas as variáveis em estudo, as misturas não diferiram entre si, a $5 \%$ de probabilidade pelo teste de Tukey.

Tabela 1. Modelos gerados para a estimativa da massa específica $\left(\mathrm{g} \mathrm{mL}^{-1}\right)$ das misturas

\begin{tabular}{ccc}
\hline Misturas & Fórmulas & $\mathbf{R}^{2}$ \\
\hline $0 \%$ ORS e 100\%OD & $\mathrm{M}=0,87813753-0,000741962 * \mathrm{~T}\left(\mathrm{c}^{\circ}\right)$ & 0,97 \\
$25 \%$ ORS e $75 \%$ OD & $\mathrm{M}=0,889684613-0,000660064 * \mathrm{~T}\left(\mathrm{c}^{\circ}\right)$ & 0,98 \\
$50 \%$ ORS e 50\%OD & $\mathrm{M}=0,90431829-0,000719204 * \mathrm{~T}\left(\mathrm{c}^{\circ}\right)$ & 0,97 \\
$75 \%$ ORS e 25\%OD & $\mathrm{M}=0,917667353-0,000720577 * \mathrm{~T}\left(\mathrm{c}^{\circ}\right)$ & 0,97 \\
$100 \%$ ORS e 0\%OD & $\mathrm{M}=0,926384364-0,000616545 * \mathrm{~T}\left(\mathrm{c}^{\circ}\right)$ & 0,98 \\
\hline
\end{tabular}

Tabela 2. Modelo para a estimativa do índice de viscosidade (cSt) das misturas

\begin{tabular}{llc}
\hline Misturas & \multicolumn{1}{c}{ Fórmulas } & $\mathbf{R}^{2}$ \\
\hline $0 \%$ ORS e $100 \%$ OD & $\mathrm{V}=(8,030067401-0,068338806) * \mathrm{~T}\left({ }^{\circ} \mathrm{C}\right)$ & 99,99 \\
$25 \%$ ORS e $75 \%$ OD & $\mathrm{V}=(13,59380883-0,1295055682) * \mathrm{~T}\left({ }^{\circ} \mathrm{C}\right)$ & 94,85 \\
$50 \%$ ORS e 50\% OD & $\mathrm{V}=\left(22,40514178-0,22931907 *\left(\mathrm{~T}^{\circ} \mathrm{C}\right)\right.$ & 95,28 \\
$75 \%$ ORS e 25\% OD & $\mathrm{V}=(38,6366593-0,40544873) *\left(\mathrm{~T}^{\circ} \mathrm{C}\right)$ & 95,10 \\
$100 \%$ ORS e 0\% OD & $\mathrm{V}=(64,89279895-0,681565452)^{*}\left(\mathrm{~T}^{\circ} \mathrm{C}\right)$ & 95,05 \\
\hline
\end{tabular}

Tabela 3. Análise do poder calorífico das misturas

\begin{tabular}{ccc}
\hline Amostra & PCS Real $\left(\mathrm{Kcal} \mathrm{Kg}^{-1}\right)$ & Ordem de maior PCS \\
\hline 0\%OSR/100\%OD & 7648,41 & $2^{\circ}$ \\
$25 \% O S R / 75 \% O D$ & 7696,41 & $1^{\circ}$ \\
$50 \% O S R / 50 \% O D$ & 7158,24 & $3^{\circ}$ \\
$75 \% O S R / 25 \% O D$ & 6734,51 & $4^{\circ}$ \\
$100 \% O S R / 0 \% O D$ & 6366,98 & $5^{\circ}$ \\
\hline
\end{tabular}


Observa-se, na Tabela 5, que, quando o trator trabalhou em ponto morto (Neutro) como carga, para as variáveis velocidade e consumo horário, as misturas não diferiram entre si, a de 5\% de probabilidade pelo teste de Tukey. Este fato deve-se ao ponto morto como carga, pois ele não ofereceu resistência que pudesse alterar os valores da velocidade e do consumo horário. Para as variáveis força de tração, potência, consumo específico e patinagem, as misturas diferiram entre si, a 5\%.

A mistura $25 \%$ OSR apresentou um melhor desempenho do trator avaliado, ou seja, maior potência $(11,05 \mathrm{~kW})$, menor consumo específico $\left(455,96 \mathrm{~g} \mathrm{~kW}^{-1} \mathrm{~h}^{-1}\right)$ e menor patinagem $(1,15 \%)$.

Conforme apresentado na Tabela 6, quando o trator trabalhou tendo a $4^{\mathrm{a}}$ marcha como carga, observou-se que as misturas, em relação às variáveis velocidade, consumo específico e patinagem, apresentam efeitos iguais, a 5\% de probabilidade, pelo teste $\mathrm{F}$. Esse resultado não era esperado, pois a variável consumo específico é função da potência e as variáveis velocidade e patinagem são função da força de tração. Para essas variáveis, potência e força de tração, o teste $\mathrm{F}$ foi significativo. Este fato pode ser explicado pelo que foi observado em campo, ou seja, quando se utilizou a $4^{\mathrm{a}}$ marcha como carga, o trator avaliado não se apresentou estável, ou seja, trepidava.

As misturas 25, 75 e $100 \%$ OSR não diferiram entre si, a $5 \%$ de probabilidade pelo teste de Tukey, e apresentaram melhor desempenho do trator avaliado, ou seja, maior potência e menor consumo horário.

Observa-se na Tabela 7 que, quando o trator trabalhou com a $3^{\mathrm{a}}$ marcha como carga, as médias dos tratamentos para as variáveis potência, consumo horário, consumo específico e patinagem apresentaram efeitos iguais, a $5 \%$ de probabilidade do teste $\mathrm{F}$.

As misturas 75 e $100 \%$ OSR não diferiram entre si, a $5 \%$ de probabilidade pelo teste de Tukey, e apresentaram melhor desempenho para o trator avaliado, ou seja, maiores velocidades.

A Tabela 8 apresenta os valores das variáveis, quando o trator trabalhou com a $2^{\mathrm{a}}$ marcha como carga. Observou-se que as misturas, em relação à variável velocidade, tiveram efeitos iguais, a $5 \%$ de probabilidade do teste $\mathrm{F}$. Esse resultado pode ser explicado pelo fato de as condições do solo terem sido as mesmas para todos os ensai-

Tabela 4. Médias das variáveis ao utilizar diferentes misturas para o trator sem carga

\begin{tabular}{|c|c|c|c|c|c|c|c|c|}
\hline MISTURA & FORÇA DE TRAÇÃO & VELOCIDADE & POTÊNCIA & CONSUMO HORÁRIO & CONSUMO ESPECÍFICO & PATINAGEM \\
\hline O\%OSR & 0 & 2,36 & a & 0 & 5,65 & a & 0 & 0 \\
\hline $25 \%$ OSR & 0 & 2,38 & a & 0 & 6,21 & a & 0 & 0 \\
\hline $50 \%$ OSR & 0 & 2,51 & a & 0 & 6,52 & a & 0 & 0 \\
\hline $75 \%$ OSR & 0 & 2,51 & a & 0 & 6,02 & a & 0 & 0 \\
\hline $100 \%$ OSR & 0 & 2,58 & a & 0 & 6,18 & a & 0 & 0 \\
\hline
\end{tabular}

As médias seguidas por, pelo menos, uma mesma letra minúscula, numa mesma coluna, não diferem estatisticamente pelo teste de Tukey a $5 \%$ de probabilidade.

Tabela 5. Médias das variáveis ao utilizar diferentes misturas quando o trator trabalhou em ponto morto (neutro)

\begin{tabular}{|c|c|c|c|c|c|c|c|c|c|c|c|c|}
\hline MISTURA & FORÇA DE TRAÇÃO & & VELOCIDADE & \multicolumn{1}{|c|}{ POTÊNCIA } & CONSUMO HORÁRIO & \multicolumn{2}{c|}{ CONSUMO ESPECÍFICO } & \multicolumn{2}{c|}{ PATINAGEM } \\
\hline O\%OSR & 3635,28 & b & 2,26 & a & 8,27 & bc & 5,46 & a & 606,91 & b & 1,28 & a \\
\hline $25 \%$ OSR & 4835,56 & a & 2,29 & a & 11,05 & a & 5,95 & a & 455,96 & c & 1,15 & ab \\
\hline $50 \%$ OSR & 3511,74 & b & 2,42 & a & 8,50 & b & 6,30 & a & 627,90 & b & 0,98 & ab \\
\hline $75 \%$ OSR & 2793,29 & c & 2,46 & a & 6,88 & bc & 5,92 & a & 731,38 & a & 0,95 & ab \\
\hline $100 \%$ OSR & 2488,46 & c & 2,47 & a & 6,15 & c & 5,93 & a & 820,35 & a & 0,62 & b \\
\hline
\end{tabular}

As médias seguidas por, pelo menos, uma mesma letra minúscula, numa mesma coluna, não diferem estatisticamente pelo teste de Tukey a $5 \%$ de probabilidade.

Tabela 6. Médias das variáveis ao utilizar diferentes misturas quando o trator trabalhou com a quarta marcha

\begin{tabular}{|c|c|c|c|c|c|c|c|c|c|c|c|c|}
\hline MISTURA & FORÇA DE TRAÇÃO & & VELOCIDADE & & POTÊNCIA & & CONSUMO HORÁRIO & & CONSUMO ESPECÍFICO & & PATINAGEM & \\
\hline 0\%OSR & 5004,16 & $a b$ & 2,43 & a & 12,14 & $a b$ & 8,72 & a & 620,76 & a & 2,34 & a \\
\hline $25 \%$ OSR & 4756,28 & $a b$ & 2,42 & a & 10,91 & $a b$ & 6,89 & b & 612,91 & a & 1,13 & a \\
\hline $50 \%$ OSR & 3945,64 & b & 2,41 & a & 9,25 & b & 6,55 & b & 536,59 & a & 0,94 & $a$ \\
\hline $75 \%$ OSR & 5584,13 & a & 2,34 & a & 13,48 & a & 6,76 & b & 525,41 & a & 0,81 & $a$ \\
\hline $100 \%$ OSR & 4546,09 & $a b$ & 2,30 & a & 11,04 & $a b$ & 6,79 & $b$ & 425,82 & a & 0,62 & $a$ \\
\hline
\end{tabular}

As médias seguidas por, pelo menos, uma mesma letra minúscula, numa mesma coluna, não diferem estatisticamente pelo teste de Tukey a $5 \%$ de probabilidade.

Rev. Ceres, Viçosa, v. 60, n.6, p. 793-801, nov/dez, 2013 
os. As misturas 75 e 100\% OSR não diferiram entre si, a $5 \%$ de probabilidade pelo teste de Tukey, e apresentaram melhores desempenhos para o trator avaliado, ou seja, maiores potência, menores consumos específicos e patinagem.

Esse resultado contraria o observado por Soranso (2006). Trabalhando com o desempenho dinâmico de um trator agrícola, utilizando biodiesel destilado etílico e metílico, o autor constatou que a utilização do motor somente com Biodiesel (B100) representou um aumento de $15,5 \%$ no consumo horário volumétrico, $18,1 \%$ no consumo horário ponderal, $16 \%$ no consumo por área trabalhada e $18 \%$ no consumo específico de combustível, em relação ao Diesel (B0).

Torres (2000), entretanto, avaliando um motor do ciclo Diesel, operando com óleo de dendê para suprimento energético em comunidades rurais, verificou diferenças de potência de 5 a $15 \%$, quando operado com óleo de dendê, com relação a óleo Diesel. Entretanto, apesar da diminuição da potência ainda é vantajoso operar essa máquina, numa propriedade rural que não disponha de energia elétrica.
Os resultados apresentados na Tabela 9, de quando o trator trabalhou com a $1^{\mathrm{a}}$ marcha como carga, demonstram que as misturas 75 e 100\% OSR não diferiram entre si, a $5 \%$ de probabilidade pelo teste de Tukey, e apresentaram melhores desempenhos do trator avaliado, ou seja, maiores velocidades e potência, menores consumo horários, consumos específicos e patinagem. Esse resultado, em comparação como consumo específico, foi contrário ao verificado por Grotta (2003), durante a avaliação de desempenho de um trator Valtra modelo BM 100, 4 cilindros com potência nominal de 73,6 kW (100 CV), em condições de campo, utilizando óleo Diesel e biodiesel de óleo residual de soja (nas proporções de 0, 25, 75 e 100\%), em que foi observado um maior consumo específico, à medida que as proporções de Biodiesel aumentaram. Segundo o autor, isso ocorreu por causa do menor poder calorífico do Biodiesel, cerca de 3 a $4 \%$ menor que o poder calorífico do Diesel.

Com relação à potência e torque, Schlosser et al. (2007), analisando o desempenho de misturas pré-aquecidas de óleo de soja cru e Diesel, como combustível para motores agrícolas, verificaram que a mistura composta por $70 \%$ de

Tabela 7. Médias das variáveis ao utilizar diferentes misturas quando o trator trabalhou com a terceira marcha

\begin{tabular}{|c|c|c|c|c|c|c|c|c|c|c|c|c|}
\hline MISTURA & FORÇA DE TRAÇÃO & & VELOCIDADE & & POTÊNCIA & & CONSUMO HORÁRIO & & CONSUMO ESPECÍFICO & & PATINAGEM & \\
\hline O\%OSR & 6408,90 & a & 2,34 & c & 15,47 & a & 9,34 & a & 613,90 & a & 3,29 & $a$ \\
\hline $25 \%$ OSR & 6014,33 & a & 2,34 & c & 14,77 & a & 9,23 & a & 598,40 & a & 2,02 & a \\
\hline $50 \%$ OSR & 5688,60 & a & 2,36 & $b c$ & 13,28 & a & 7,86 & a & 521,22 & a & 0,97 & a \\
\hline $75 \%$ OSR & 5448,71 & a & 2,41 & $a b$ & 12,77 & a & 7,72 & a & 432,47 & a & 0,93 & a \\
\hline $100 \%$ OSR & 5310,02 & a & 2,46 & a & 12,51 & a & 7,54 & a & 451,96 & a & 0,26 & a \\
\hline
\end{tabular}

As médias seguidas por, pelo menos, uma mesma letra minúscula, numa mesma coluna, não diferem estatisticamente pelo teste de Tukey a $5 \%$ de probabilidade.

Tabela 8. Médias das variáveis ao utilizar diferentes misturas quando o trator trabalhou com a segunda marcha

\begin{tabular}{|c|c|c|c|c|c|c|c|c|c|c|c|c|}
\hline MISTURA & FORÇA DE TRAÇÃO & & VELOCIDADE & & POTÊNCIA & & CONSUMO HORÁRIO & & CONSUMO ESPECÍFICO & & PATINAGEM & \\
\hline $0 \%$ OSR & 7501,63 & $b$ & 2,33 & $a$ & 17,20 & $b$ & 9,78 & $a$ & 483,43 & $a$ & 3,79 & $a b$ \\
\hline $25 \%$ OSR & 8751,70 & a & 2,31 & a & 20,21 & a & 10,62 & a & 447,01 & $a b$ & 5,55 & a \\
\hline $50 \%$ OSR & 7735,17 & $b$ & 2,30 & a & 17,56 & $a b$ & 8,17 & $b$ & 396,45 & b & 2,06 & $b c$ \\
\hline $75 \%$ OSR & 8610,35 & a & 2,29 & a & 19,81 & $a b$ & 9,67 & a & 415,03 & b & 2,63 & $b c$ \\
\hline $100 \%$ OSR & 8209,02 & $a b$ & 2,27 & a & 19,14 & $a b$ & 9,79 & a & 435,14 & $a b$ & 1,08 & c \\
\hline
\end{tabular}

As médias seguidas por, pelo menos, uma mesma letra minúscula, numa mesma coluna, não diferem estatisticamente pelo teste de Tukey a $5 \%$ de probabilidade.

Tabela 9. Médias das variáveis ao utilizar diferentes misturas quando o trator trabalhou com a primeira marcha

\begin{tabular}{|c|c|c|c|c|c|c|c|c|c|c|c|c|}
\hline MISTURA & FORÇA DE TRAÇÃO & & VELOCIDADE & & POTÊNCIA & & CONSUMO HORÁRIO & \multicolumn{2}{c|}{ CONSUMO ESPECÍFICO } & PATINAGEM \\
\hline 0\%OSR & 12738,72 & a & 2,13 & a & 27,13 & a & 10,94 & ab & 342,34 & b & 4,43 & b \\
\hline $25 \%$ OSR & 12040,96 & a & 2,03 & b & 24,47 & ab & 11,79 & a & 410,60 & a & 7,31 & a \\
\hline $50 \%$ OSR & 10134,52 & b & 2,14 & a & 21,71 & b & 10,28 & b & 403,02 & a & 2,39 & bc \\
\hline $75 \%$ OSR & 12217,96 & a & 2,12 & a & 25,83 & a & 11,42 & ab & 375,90 & ab & 3,38 & bc \\
\hline $100 \%$ OSR & 11747,81 & a & 2,13 & a & 25,07 & ab & 11,52 & ab & 391,23 & ab & 2,14 & c \\
\hline
\end{tabular}

As médias seguidas por, pelo menos, uma mesma letra minúscula, numa mesma coluna, não diferem estatisticamente pelo teste de Tukey a $5 \%$ de probabilidade. 
óleo vegetal e 30\% de óleo Diesel, com preaquecimento na faixa de $68{ }^{\circ} \mathrm{C}$, apresentou uma potência média superior em $8,7 \%$, em relação à média da testemunha e, em elevados regimes de rotação, foi superior em 14,0\%.

Masiero et al. (2011), ao avaliarem a determinação do rendimento na barra de tração de tratores agrícolas com tração dianteira auxiliar (4x2 TODA), observaram que, nas superfícies trativas avaliadas, os valores médios de rendimento na barra variaram em função do modelo e potência do trator, além de variar também em função do tipo de pneu, pressão de inflação, velocidade de deslocamento e relação entre peso e potência do motor. Essa grande variação, em função da relação entre peso e potência do motor, em diferentes marcas de tratores, também correspondeu aos resultados encontrados por Lanças (1996), Monteiro (2009) e Schlosser et al. (2005).

Lanças (1996), analisando o desempenho operacional de pneus radiais em função da pressão de inflação, da lastragem e do deslizamento das rodas de tratores agrícolas, afirma que as condições superficiais do solo firme apresentam melhores resultados de eficiência trativa, comparando-se com as do solo preparado (mobilizado). Isso se deve aos fenômenos da patinagem, que provocam a redução no avanço do trator, e ao recalque ou afundamento do rodado, no solo, que aumenta a resistência ao rolamento (Mialhe, 1991).

Monteiro et al. (2013), ao avaliarem o Rendimento na barra de tração de um trator agrícola com diferentes relações de peso e potência, observaram que, entre as relações de peso e potência, o maior rendimento na barra de tração do conjunto moto mecanizado foi obtido para a relação peso potência de $60 \mathrm{~N} \mathrm{~kW}^{-1}$, nas cargas aplicadas na barra de tração, com amplitude de 25 a $40 \mathrm{kN}$ e os melhores rendimentos da barra de tração do trator foram obtidos quando se aplicaram cargas na barra de tração de 25 a $30 \mathrm{kN}$, nas relações entre o peso e a potência de 50 e $55 \mathrm{~N} \mathrm{~kW}^{-1}$, mostrando ser a amplitude de carga mais adequada ao conjunto avaliado.

Com o aumento das cargas aplicadas ao trator avaliado, os melhores resultados observados no rendimento do trator foram verificados com o aumento das percentagens de mistura (25\% OSR para carga N, 25 , 75 e 100\% OSR, para a $4^{\mathrm{a}}$ marcha como carga, e 75 e $100 \%$ OSR, para a $3^{\mathrm{a}}$, $2^{\mathrm{a}}$ e $1^{\mathrm{a}}$ marchas como carga). Esse resultado é interessante, pois, em situação real de campo, trabalha-se com cargas maiores, e trabalhando-se com maior percentagem de mistura, tem-se maior rendimento do trator e melhor reaproveitamento do óleo de soja.

\section{CONCLUSÃO}

A massa específica das misturas aumenta com o aumento da percentagem de OSR e diminui com o aumento da temperatura;
O aquecimento da mistura de $100 \%$ OSR, de 40 para 90 ${ }^{\circ} \mathrm{C}$, reduziu em até $90,4 \%$ a sua viscosidade;

O poder calorífico da mistura de $25 \%$ OSR e $75 \%$ OD foi mais próximo ao do OD, com diferença de apenas 48 kcal;

A potência máxima encontrada, de $27,13 \mathrm{~kW}$, foi verificada na mistura de $100 \%$ OD com $0 \%$ OSR;

As misturas com maior percentagem de OSR apresentam maior consumo em relação ao do OD;

A mudança da percentagem da mistura de combustível provocou variação no torque do motor, sendo que a mistura de $100 \%$ OD com $0 \%$ OSR apresentou o maior valor;

A mistura 50\% OSR foi a que apresentou os piores resultados para as cargas estudadas;

O OSR mostrou-se uma alternativa viável para ser utilizado em misturas com OD para acionamento de motores.

\section{REFERÊNCIAS}

ANP - Agência Nacional do Petróleo (2001) Portaria $n^{\circ} 310$, de 27 de dezembro de 2001. Estabelece as especificações para comercialização de óleo diesel automotivo em todo o território nacional e define obrigações dos agentes econômicos sobre o controle de qualidade do produto. Diário Oficial da União, Brasília, 28 de dezembro de 2001.

Barnes HA, Hutton JF \& Walters K (1991) An Introduction to Rheology. $1^{a}$ ed. New York, Elsevier Science. 199p.

Barguer EL, Liljedahl JB, Carleton WM \& Mckibben EG (1966) Tratores e seus motores. São Paulo, Edgar Blucher. 398p.

Castro AA (1999) Extração, caracterização físico-química, nutricional e reológica do azeite do coco babaçu (Orbignyaspp). Dissertação de Mestrado. Universidade Federal da Paraíba, Campina Grande. 65p.

Faria ID (2010) Aspectos físico-químicos e ambientais dos combustíveis. Centro de Estudos e da Consultoria do Senado. Distrito Federal. (Textos para Discussão 73.) p.6. ISSN 1983-0645.

Fender TR (2009) Por que usar óleo vegetal puro como combustível? Disponível em: <http://www.viajus.com.br/ viajus.php? pagina $=$ artigos\&id=16>. Acessado em: 22 de julho de 2009

Grotta DCC (2003) Desempenho de um trator agrícola em operação de gradagem utilizando biodiesel etilíco filtrado de óleo residual como combustível. Dissertação de Mestrado. Faculdade de Ciências Agrárias e Veterinárias de Jaboticabal, Jaboticabal. $44 \mathrm{p}$.

Inoue GH (2008) Utilização de óleo vegetal em motor estacionário de ciclo diesel. Tese de Doutorado. Universidade Federal de Viçosa, Viçosa. 102p.

Knothe G (2006) A história dos combustíveis derivados de óleos vegetais. In: Knothe G, Van Gerpen J \& Krahl J (Eds.) Manual de Biodiesel. São Paulo, Editora Blucher. p.05-18.

Lanças KP (1996) Desempenho operacional de pneus radiais em função da pressão de inflação, da lastragem e do deslizamento das rodas de tratores agrícolas. Tese de Doutorado. Faculdade de Ciências Agronômicas, Botucatu. 171p. 
Lima LR \& Marcondes AA (2002) Álcool carburante: uma estratégia brasileira. Curitiba, UFPR. 246p.

Masiero FC, Lanças KP \& Monteiro LA (2011) Determinação do rendimento na barra de tração de tratores agrícolas com tração dianteira auxiliar (4x2 TDA). Revista Engenharia na Agricultura, 26:55-73

Mialhe, L. G (1996) Máquinas agrícolas: Ensaios \& Certificações. Piracicaba, SP: Fundação de estudos agrários Luiz de Queiroz. $538 \mathrm{p}$.

Monteiro LA, Albiero D, Souza FH, Melo RP \& Cordeiro IM (2013) Rendimento na barra de tração de um trator agrícola com diferentes relações de peso e potência. Revista Ciência Agronômica, 44:70-75.

Monteiro LA (2009) Desempenho operacional e energético de um trator agrícola em função do tipo de pneu, velocidade de deslocamento, lastragem líquida e condição superficial do solo. Dissertação de Mestrado. Faculdade de Ciências Agronômicas, Botucatu. 69p.

Pramanik K (2003) Properties and use of Jatropha curcas oil and diesel fuel blends in compression ignition engine. Renewable Energy, 28:239-248

Ribeiro RA, Queiroz MGMN, Alves VL, Prata ERBA, Barbosa ES, Santos E \& Mota BSN (2010) Efeitos do tempo de armazenamento sobre as propriedades físico-químicas de óleo de Jatropha curcas (Pinhão Manso). Revista Brasileira de Oleaginosas e Fibrosas, 14:1-7.
Siqueira WC (2010) Utilização de misturas de óleo Diesel e óleo de soja reutilizado em um trator agrícola de pneus. Dissertação de Mestrado. Universidade Federal de Viçosa, Viçosa. 69p.

Schlosser JF, Debiasi H, Willes JÁ \& Machado ODC (2005) Análise comparativa do peso específico dos tratores agrícolas fabricados no Brasil e seus efeitos sobre a seleção e uso. Ciência Rural, 35:92-97.

Schlosser JF, Machado PRM \& Camargo MN (2007) Desempenho de misturas pré aquecidas de óleo de soja cru e Diesel como combustível para motores agrícolas. Ciência Rural, 37:13291335 .

Soranso AM (2006) Desempenho dinâmico de um trator agrícola utilizando biodiesel destilado etílico e metílico. Dissertação de Mestrado. Universidade Estadual do Oeste do Paraná, Cascavel. $68 \mathrm{p}$.

Torres EA (2000) Avaliação de um motor do ciclo diesel operando com óleo de dendê para suprimento energético em comunidades rurais. In. $3^{\circ}$ Encontro de Energia no Meio Rural, Campinas. Anais, UNICAMP/SBEA. Disponível em: <http:// www.proceedings.scielo.br/scielo.php?script=sci_arttext\&pid= MSC $0000000022000000200049 \& \operatorname{lng}=\mathrm{en} \& \mathrm{nrm}=\mathrm{abn}>$. Acessado em: 30 de novembro de 2013.

Vidal JWB (2009) Heranças do petróleo. In: Uczai P (Ed.) Inevitável Mundo Novo: a relação entre energias renováveis, produção de alimentos e o futuro do planeta. Chapecó, Pallotti. 376p.

Wust E (2004) Estudo da viabilidade técnico-científica da produção de biodiesel a partir de resíduos gordurosos. Dissertação de Mestrado. Universidade Regional de Blumenau, Blumenau. 113p. 